Research Paper

\title{
Mast Cell-Nerve Cell Interaction at Acupoint: Modeling Mechanotransduction Pathway Induced by Acupuncture
}

\author{
Wei Yao, Hongwei Yang, Na Yin, and Guanghong Ding ${ }^{\bowtie}$ \\ Department of Mechanics and Engineering Science, Fudan University, 220 Handan Road, Shanghai, 200433, China. \\ $\square$ Corresponding author: Guanghong Ding, Department of Mechanics and Engineering Science, Fudan University, 220 Handan Road, \\ Shanghai, 200433, China.
}

(ㅇ Ivyspring International Publisher. This is an open-access article distributed under the terms of the Creative Commons License (http://creativecommons.org/ licenses/by-nc-nd/3.0/). Reproduction is permitted for personal, noncommercial use, provided that the article is in whole, unmodified, and properly cited.

Received: 2014.01.2I; Accepted: 2014.03.27; Published: 20I4.04.26

\begin{abstract}
Mast cells are found abundant at sites of acupoints. Nerve cells share perivascular localization with mast cells. Acupuncture (mechanical stimuli) can activate mast cells to release adenosine triphosphate (ATP) which can activate nerve cells and modulates pain-processing pathways in response to acupuncture. In this paper, a mathematical model was constructed for describing intracellular $\mathrm{Ca}^{2+}$ signal and ATP release in a coupled mast cell and nerve cell system induced by mechanical stimuli. The results showed mechanical stimuli lead to a intracellular $\mathrm{Ca}^{2+}$ rise in the mast cell and ATP release, ATP diffuses in the extracellular space (ECS) and activates the nearby nerve cells, then induces electrical current in the nerve cell which spreads in the neural network. This study may facilitate our understanding of the mechanotransduction process induced by acupuncture and provide a methodology for quantitatively analyzing acupuncture treatment.
\end{abstract}

Key words: Mast Cell, Nerve Cell, Ca2+ Signaling, ATP Release, Acupuncture.

\section{Introduction}

Mechanical stimuli have been applied to the skin for medical treatment in traditional Chinese medicine (TCM). As one basic technique in TCM, acupuncture is a method of applying mechanical stimuli by inserting needles into specific parts (acupoints) abundant of mast cells ${ }^{[1]}$. When the needle is twirled, lifted and thrusted, the winding of collagen on the acupuncture needle changes the interstitial microenvironment ${ }^{[2-3]}$. Although western medicine has treated acupuncture with considerable skepticism [4], emerging research implies acupuncture is effective for some conditions. In 2004, the NIH issued a Consensus Statement on Acupuncture, supporting the use of acupuncture for adult postoperative and chemotherapy nausea and vomiting, symptomatic control of pain, gastrointestinal disease treatment and stroke rehabilitation, etc [5]. However, the biological basis of the acupuncture effects remains unknown. Recent emerging evidence suggests the possibility that mast cell-nerve cell interaction contributes to modulating signal transmission pathways ${ }^{[6]}$.

Mast cells are common at sites that are in close contact with the external environment (skin, gastrointestinal tract and airways), they are distributed in virtually all organs and vascularized tissues [7]. They are best known for their involvement in allergic reactions, in which IgE attaches to the Fc $\varepsilon$ receptor on the mast cell surface and leads to a variety of mediators release after cross linking of surface-bound $\operatorname{IgE}$ by allergen. Nowadays, mast cells are found abundant at sites of acupoints [8]. Our experiments showed acupuncture resulted in a remarkable increase in degranulation of the mast cells [9]. Pretreatment of the acupuncture point with disodium chromoglycate (DSCG, mast cell stabilizer) not only counteracted the phenomenon of degranulation but also reduced analgesic effect of acupuncture [8]. Further experiments showed mechanical stimuli can activate mast cells and 
allow $\mathrm{Ca}^{2+}$ inflow into the cell, which in turn induce mast-cell degranulation and mediators release [10-11]. These evidences demonstrate the possible role of mast cells in acupuncture effects. Nerve cells share perivascular localization with mast cells [12]. The specificity of mast cell-nerve cell spatial contacts has been demonstrated in vitro [13] and in vivo [14]. Mast cell-nerve cell associations have been found in the myocardium [15], diaphragm [16], brain [17], gallbladder, ileum, mesentery, and skin of a variety of animals at both the anatomic and molecular levels, pointing to their fundamental interdependence [18]. Mast cells are able to take up, store, and release a variety of biogenic amines through which they participate in physiological reactions. Mast cells' mediators can sensitize sensory neurons, which further activates mast cells by releasing neurotransmitters or neuropeptides. It is supposed purinergic receptors may be involved in mast cell-nerve cell interactions [19]; e.g. ATP gates purinergic receptors, plays a key role in transmission of pain signals in the body [20], ATP releases from mast cells when activated, ATP activates membrane current in nerve cells then modulate body function.

Mathematical models have been developed for describing signal transmission pathways for mast cells and nerve cells respectively. Xu et al. has established a nociceptor model to study the underlying mechanisms in the process of skin thermal pain [21-22]. Their model can contribute to the understanding of biothermomechanical- neurophysiological behavior of skin tissue [23]. Bennet et al. proposed an astrocytes network model to investigate $\mathrm{Ca}^{2+}$ wave ${ }^{[24]}$. In their models, activation of purinergic receptors by extracellular ATP is an important component of the response to pain in the neural system; $E_{\mathrm{m}}$ depolarizations and intracellular $\mathrm{Ca}^{2}{ }^{+}$waves propagation are the main signal transmission. Zhou et al. investigated action potential through a single branch point of a myelinated nerve fiber with a parent branch bifurcating into two identical daughter branches [25]. To investigate the mechanism of mast cells' response to physical stimuli, Shi et al. has set up a mathematical model to simulate intracellular $\mathrm{Ca}^{2}+$ signals and degranulation to laser radiation [26]. We have set up a mathematical model to explore signaling pathways in mast cells and clarified mast cells participating in acupuncture effect [27]. However, there exist no mathematical models investigating signal transmission pathways modulated by acupuncture based on mast cell-nerve cell interaction.

In this paper, we construct a mathematical model for describing intracellular $\mathrm{Ca}^{2+}$ signal and ATP release in a coupled mast cell and nerve cell system induced by mechanical stimuli. We introduce methods of the coupled model in section 2 and present numerical simulations under a variety of conditions in section 3. This model may explain the mechanotransduction pathway induced by mechanical stimuli.

\section{Methods}

The dynamic process of mechanotransduction pathway induced by mechanical stimuli is simplified as following (Fig. 1): Acupuncture (mechanical stimuli) activates mechano-sensitive (MS) ion channels on mast cells membrane [10] and allow $\mathrm{Ca}^{2+}$ entry, local intracellular $\mathrm{Ca}^{2+}$ rise induces a cascade of intracellular signaling events including ATP release, therefore, increase interstitial adenosine and ATP concentrations at acupoint [28-29], ATP diffuses in ECS and activates adjacent nerve terminals and triggers action potential, which will spread in neural network (through branches of nerve fiber) and modulate the multiple pain-processing pathways in response to acupuncture.

\section{I Continuum model}

Micro-tissue around acupoint is described as axisymmetric continuum and polar coordinates are employed. A mast cell $\left(\mathrm{MC}_{0}\right)$ locates at $r=0$ and the tissue space occupied by other cells is considered as homogeneous. Nerve cells locate some distance $(r=$ Dis, Dis=20, 40, 60, $\cdots, 1000 \mu \mathrm{m})$ from $\mathrm{MC}_{0}$ and can be activated by neurotransmitter (ATP) released from mast cells. To make the problem computationally tractable, the specific geometries of mast cell and nerve cell are not considered. Since this is a continuum model, the concept of individual cell is not meaningful. Cellular properties refer to the average values at any location within the tissue. The model includes three compartments: mast cell cytosolic space, nerve cells (sensory neuron and its fibers) cytosolic space and the ECS. ECS is considered as one continuum space, the corresponding interstitial ions and neurotransmitters concentrations are described in polar coordinates by standard reaction-diffusion equations of the form

$$
\frac{\partial[\mathrm{ATP}]_{e}}{\partial t}=\nabla \cdot\left(D_{A T P, e} \nabla[\mathrm{ATP}]_{e}\right)+[\mathrm{ATP}]_{\text {production }}=\frac{1}{r} \frac{\partial}{\partial r}\left(r D_{\text {ATP, },} \frac{\partial[\mathrm{ATP}]_{e}}{\partial r}\right)+[\mathrm{ATP}]_{\text {production }}
$$

where $D_{\text {ATP, }}$ is the interstitial diffusion coefficient of ATP and [ATP $]_{\text {production }}$ is ATP release from cells. 
We supposed ATP releases only from mast cell. It was proposed that PKC acts as the important agent that triggers bio-mediators release from mast cell [20, 27].

$$
\frac{d[\mathrm{ATP}]}{d t}=V_{A T P} \xi \max \left\{\left[P K C_{A}\right]-\left[P K C_{A}\right]_{\min }, 0\right\}
$$

where $V_{\mathrm{ATP}}$ is ATP production rate. $\left[P K C_{\mathrm{A}}\right]$ is the active $\mathrm{PKC}$ concentration, $\left[\mathrm{PKC}_{\mathrm{A}}\right]_{\min }$ is the threshold concentration, which is necessary to prevent small amounts of $\left[\mathrm{PKC}_{A}\right]$ from being amplified and thus leading to ATP release. $\xi$ is a parameter that accounts for depletion of ATP inside the cell. $\xi$ has initial value 1 and decreases according to $\frac{\partial \xi}{\partial t}=-k_{\text {loss }} \xi \frac{\max \left\{\left[\mathrm{PKC}_{A}\right]-\left[\mathrm{PKC}_{A}\right]_{\min }, 0\right\}}{K_{r e l}+\left[\mathrm{PKC}_{A}\right]}$, where $k_{\text {loss }}$ is the depletion rate parameter, and $K_{\text {rel }}$ is the kinetic parameter [30].

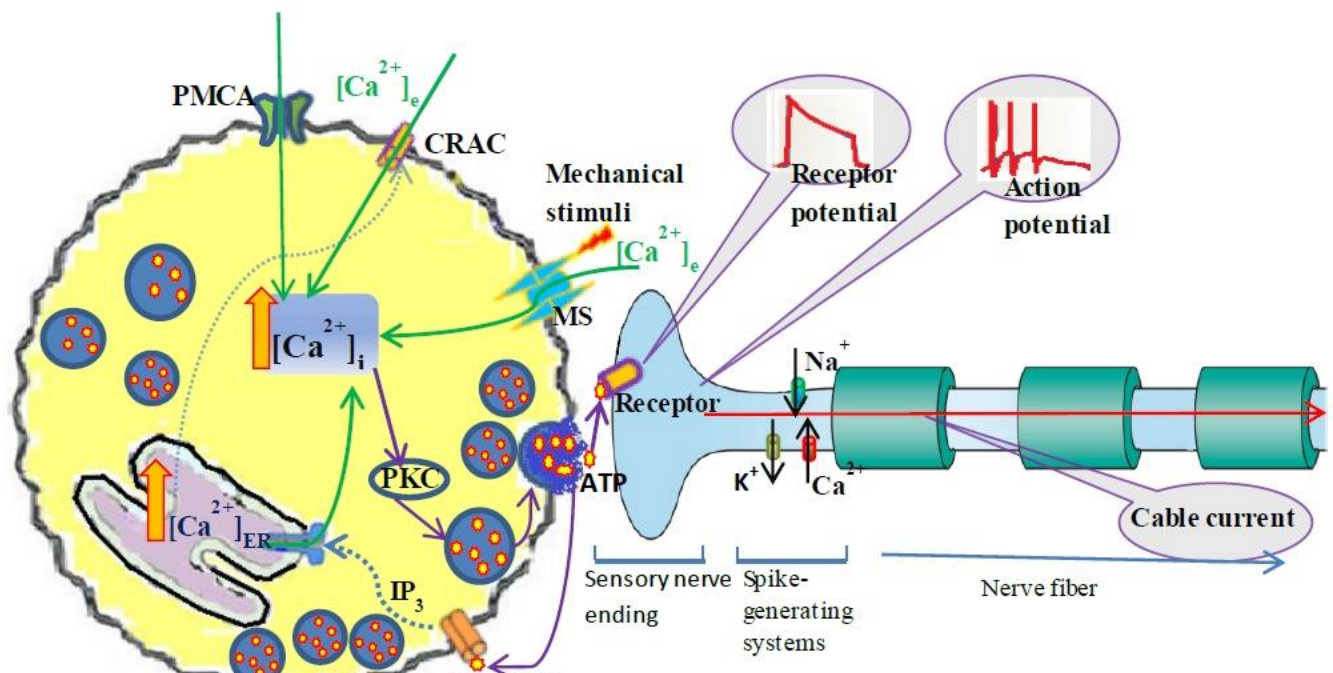

Mast Cell

Nerve Cell

Figure I. Schematic diagram of the coupled mast cell and nerve cell model. Mast Cell is activated by mechanical stimuli; the steps leading from MS channel activation to $\mathrm{Ca}^{2+}$ release from the calcium store (ER) into the cytosol and ATP release into ECS. ATP diffuses in ECS and binds to purinergic receptors of adjacent nerve terminals (sensory neuron) and triggers action potential which induces passive electrical flow spreading along branches of nerve fiber in neural networks.

\subsection{Ion currents in mast cell}

The major stage in this process is $\mathrm{Ca}^{2+}$ entry through ion channels in membrane. $\mathrm{Ca}^{2+}$ currents between cells and ECS are described in Fig. 1. There are MS (mechano-sensitive) $\mathrm{Ca}^{2+}$ current $\left(I_{\mathrm{Ca}, \mathrm{MS}}\right), \mathrm{CRAC}\left(\mathrm{Ca}^{2+} \mathrm{re}^{-}\right.$ lease-activated $\mathrm{Ca}^{2+}$ ) current $\left(I_{\mathrm{CRAC}}\right)$ and PMCA (plasma membrane $\mathrm{Ca}^{2+}$-ATPase) $\mathrm{Ca}^{2+}$ current $\left(I_{\mathrm{PMCA}}\right)$ in mast cells.

The second stage is the regulation of metabotropic receptor activities. It starts from the binding of ligand (ATP) to receptors and leads to, via a G-protein cascade, the production of $\mathrm{IP}_{3}$ and the release of $\mathrm{Ca}^{2+}$ from endoplasmic reticulum (ER) ${ }^{[17,31]}$. ER behaves as a $\mathrm{Ca}^{2+}$ store and exchanges $\mathrm{Ca}^{2+}$ with the cytosol via $\mathrm{IP}_{3}$ sensitive channels $\left(J_{\text {Ip3 }}\right)$, calcium pumps $\left(J_{\text {pump }}\right)$ and leaks $\left(J_{\text {leak }}\right)$, as described by Bennett et al ${ }^{[30]}$.

The detailed processes are given in one of our paper online first [27].

\subsection{Ion currents in nerve cell}

The Hodgkin-Huxley $(\mathrm{HH})$ model considered the long axon of a nerve cell with two ions, $\mathrm{Na}^{+}$and $\mathrm{K}^{+}$, we add $\mathrm{Ca}^{2+}$ in addition. Besides following the same equations of $\mathrm{HH}$ model, we added ATP-activated channels according to recent research [32]. Tan et al. found four types (F, I, S and VS) of ATP-activated cationic current and the VS type dominates the total current; therefore, we include VS current in the model. Including other three types of current makes no essential difference to the results of the model. We use GHK model to describe the VS current (Eq.3) which is suitable when there is a large difference in concentrations in the intracellular space (ICS) and ECS compartment [33]. 


$$
I_{\text {ATP,ion }}=g_{\text {ATP }} m h \frac{F E_{m}\left(\left[\text { ion }_{i}-\exp \left(-\frac{E_{m}}{\phi}\right)[\text { ion }]_{e}\right)\right.}{\phi\left(1-\exp \left(-\frac{E_{m}}{\phi}\right)\right)} \frac{[A T P]}{[A T P]+[A T P]_{\text {act } 1 / 2}}
$$

Where $g_{\text {ATP }}$ is the permeability of ATP-activated channel per second; $F$ is the Faraday constant; $E_{\mathrm{m}}$ is the membrane potential; $\phi=R T / z F$ is a parameter where $R$ is the universal gas constant, $T$ is the absolute temperature, $z$ is the valence of ion; [ion] $]_{i}$ and [ion] $]_{\mathrm{e}}$ are intracellular and extracellular $\mathrm{Na}^{+}, \mathrm{K}^{+}$and $\mathrm{Ca}^{2+}$ concentration respectively; $m$ and $h$ are the activation and inactivation gating variables, respectively, satisfy the following equations when the channels are activated by ATP $\left(10^{-5} \mathrm{M}\right.$ to $\left.10^{-3} \mathrm{M}\right){ }^{[32] \text { : }}$

$$
\begin{aligned}
& \frac{d m}{d t}=\alpha_{m}(1-m)-\beta_{m} m \\
& \frac{d h}{d t}=\alpha_{h}(1-\mathrm{h})-\beta_{h} h
\end{aligned}
$$

We are interested in $\mathrm{Ca}^{2+}$ Dynamic, therefore, outward pump fluxes ( $\left.I_{\mathrm{Pump}}\right)$ and inward passive fluxes $\left(I_{\mathrm{L}, \mathrm{Ca}}\right)$ are included in cell membrane according to Friel [34]. ER exchanges $\mathrm{Ca}^{2+}$ with the cytosol via $J_{\mathrm{Ip} 3} J_{\text {pump }}$ and $J_{\text {leak }}$ following a same scheme as that in mast cell.

\section{4 $\mathrm{Ca}^{2+}$ Dynamic in mast cell and nerve cell}

The ER $\mathrm{Ca}^{2+}$ dynamics is governed by $\mathrm{Ca}^{2+}$ release from ER

$$
\frac{d\left[C a^{2+}\right]_{E R}}{d t}=-\beta\left(J_{I p 3}+J_{\text {leak }}-J_{p u m p}\right)
$$

Where $\beta$ is the $\mathrm{Ca}^{2+}$ buffering factor ${ }^{[31]}$.

Then cytoplasm $\mathrm{Ca}^{2+}$ dynamics is governed by cross-membrane $\mathrm{Ca}^{2+}$ flow and $\mathrm{Ca}^{2+}$ release from ER

$$
\begin{array}{ll}
\frac{d\left[\mathrm{Ca}^{2+}\right]_{i}}{d t}=-\left(I_{C R A C}+I_{C a, M S}+I_{P M C A}\right)+\gamma \beta\left(J_{I P 3}+J_{\text {leak }}-J_{\text {pump }}\right) & \text { (in mast cell) } \\
\frac{d\left[C a^{2+}\right]_{i}}{d t}=-\left(I_{A T P, C a}+I_{L, C a}+I_{\text {pump }}\right)+\gamma \beta\left(J_{I p 3}+J_{\text {leak }}-J_{\text {pump }}\right) \quad \text { (in nerve cell) }
\end{array}
$$

Where $r$ is the ratio of ER volume to cytoplasm volume.

\subsection{Passive electrical flow in nerve cell}

We apply cable theory which describes the relationship between current and voltage in a one-dimension cable to study electrical signaling along nerve cells [35]. We discretize the cable model by replacing the partial derivatives by difference formulas on equally distributed grid points $0=x_{0}<x_{1}<x_{2}<\cdots<x_{N}=L$ with size $\delta x$. The discretization uses centered difference formula

$$
C_{m} \frac{\partial E_{\mathrm{m}, \mathrm{j}}}{\partial t}=-I_{j}+\frac{d}{4 R a} \frac{E_{\mathrm{m}, \mathrm{j}+1}+E_{\mathrm{m}, \mathrm{j}-1}-2 E_{\mathrm{m}, \mathrm{j}}}{\delta x^{2}}
$$

Where $C_{\mathrm{m}}$ is the specific capacitance of the membrane, subscript $j$ means the $j^{\text {th }}$ compartment, $d$ is the diameter of the nerve cell and simplified as constant in this model, $R a$ is the axial resistance, $I_{\mathrm{j}}$ is the total membrane ionic current,

$$
I_{j}=\left[g_{N a}\left(E_{\mathrm{m}}-E_{N a}\right)+g_{K}\left(E_{\mathrm{m}}-E_{K}\right)+g_{L}\left(E_{\mathrm{m}}-E_{L}\right)\right]+I_{A T P, K}+I_{A T P, N a}+I_{A T P, C a}+I_{L, C a}+I_{p u m p}
$$

Where $g_{N a}\left(E_{\mathrm{m}}-E_{N a}\right)+g_{K}\left(E_{\mathrm{m}}-E_{K}\right)+g_{L}\left(E_{\mathrm{m}}-E_{L}\right)$ are $\mathrm{Na}^{+}, \mathrm{K}^{+}$and leak current described by Hodgkin-Huxley [36], $I_{\mathrm{ATP}}$, ion (ion $=\mathrm{Na}^{+}, \mathrm{K}^{+}$and $\mathrm{Ca}^{2+}$ ) is the ATP current described by Eq. 3 .

\subsection{Calculation and Parameters}

The differential equation (1) is solved on a spatial domain $0<r<L$. The equation is first discretized by replacing the partial derivatives in $r$ by difference formulas on equally distributed grid points $0=r_{0}<r_{1}<r_{2}<\cdots$ $<r_{N}=L$ with size $\Delta r$. The discretization using centered difference formula (notice ATP produced only at $j=0$ ) 


$$
\begin{aligned}
& \frac{[A T P]_{e, j}^{n+1}-[A T P]_{e, j}^{n}}{\Delta t}=\frac{D_{A T P, e}}{r_{j} \Delta r^{2}}\left(r_{j+\frac{1}{2}}\left([A T P]_{e, j+1}^{n}-[A T P]_{e, j}^{n}\right)-r_{j-\frac{1}{2}}\left([A T P]_{e, j}^{n}-[A T P]_{e, j-1}^{n}\right)\right) \\
& =D_{A T P, e}\left(\frac{[A T P]_{e, j+1}^{n}+[A T P]_{e, j-1}^{n}-2[A T P]_{e, j}^{n}}{\Delta r^{2}}+\frac{[A T P]_{e, j+1}^{n}-[A T P]_{e, j-1}^{n}}{2 r_{j} \Delta r^{2}}\right)(j>0)
\end{aligned}
$$

Special care is needed to handle the coordinate singularity at $r=0$. In this paper, we use the fact that we have radial symmetry at $r=0$. Thus, we can simply discretize the formula

$$
\frac{[A T P]_{e, 0}^{n+1}-[A T P]_{e, 0}^{n}}{\Delta t}=\frac{4 D_{A T P, e}}{\Delta r^{2}}\left([A T P]_{e, 1}^{n}-[A T P]_{e, 0}^{n}\right)+[A T P]_{p r o d u c t i o n, 0}
$$

Equations (1)-(7) are solved using a built-in Matlab solver ode15 with proper initial and boundary conditions. We have carried our simulations by applying mechanical stimuli at $r=0$.

\section{Results}

\section{I Mast cell's response to mechanical stimuli}

According to the model, mechanical stimuli to a single mast cell leads to both a $\left[\mathrm{Ca}^{2+}\right]_{\mathrm{i}}$ rise as well as ATP release, which increases $[\mathrm{ATP}]_{\mathrm{e}}$ and then acts on $\mathrm{P}_{2}$-receptors of the cell in an autocrine manner. Fig. 2 shows the response of mast cell to mechanical stimuli. First is a fast $\left[\mathrm{Ca}^{2+}\right]_{i}$ rise (Fig. 2a) because of $\mathrm{Ca}^{2+}$ influx from ECS through the MS channels. In one hand, local intracellular $\mathrm{Ca}^{2+}$ rise activates PKC (Fig. 2b) and increase the sensitivity of secretory granules to $\mathrm{Ca}^{2+}$, thus driving ATP release (Fig. $2 \mathrm{c}$ ) ${ }^{[8]}$. In the other hand, $\left[\mathrm{IP}_{3}\right]$ rise due to $\left[\mathrm{Ca}^{2+}\right]_{\mathrm{i}}$ increasing (Fig. 2d); $\mathrm{IP}_{3}$ interacts with receptors $\left(\mathrm{IP}_{3} \mathrm{R}\right)$ on the endoplasmic reticulum (ER) leading the release of stored $\mathrm{Ca}^{2+}$ and the depletion of $\mathrm{Ca}^{2+}$ in ER triggers $\mathrm{Ca}^{2+}$ entry through CRAC channels, therefore leads to further $\left[\mathrm{Ca}^{2+}\right]_{\mathrm{i}}$ rise. Fig.2a shows there is an obvious $\left[\mathrm{Ca}^{2+}\right]_{i}$ rise begin at $t=18 \mathrm{~s}$ which is accordance to $\left[\mathrm{IP}_{3}\right]$ rise at $\mathrm{t}=18 \mathrm{~s}$ or so (Fig. $2 \mathrm{~d}$ ).
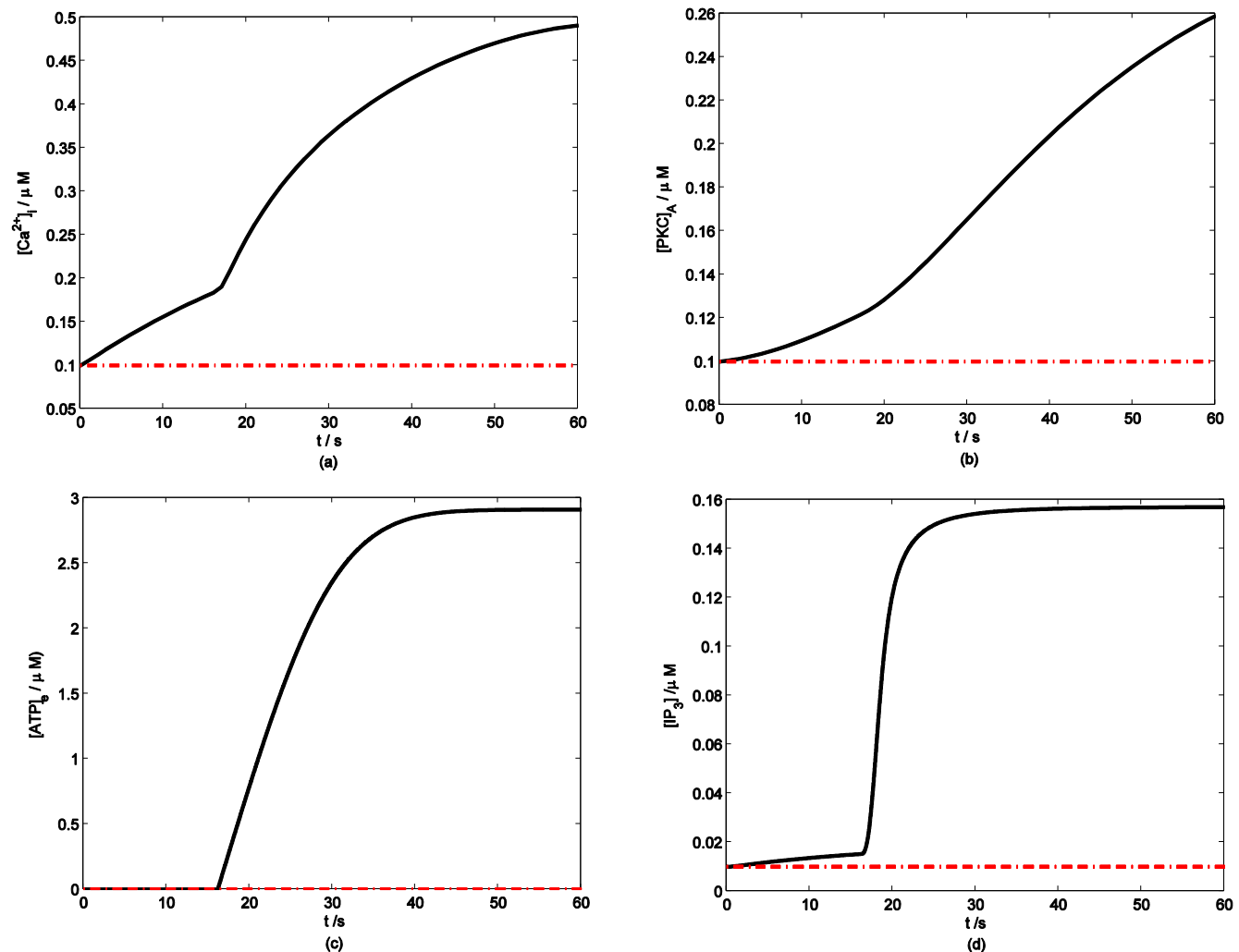

Figure 2 Changes in $\left[\mathrm{Ca}^{2+}\right]_{1},[\mathrm{PKC}]_{\mathrm{A}},[\mathrm{ATP}]_{\mathrm{e}}$ and $\left[\mathrm{IP}_{3}\right]$ in a single isolated mast cell model, as functions of time $(\mathrm{t})$. Solid line represents simulation results after exposure to an initiating mechanical stimuli during time $t=0-60$ s, dash line represents the stable state without stimuli. (a) immediately [Ca $\left.{ }^{2+}\right]$ i rise. (b) $\left[\mathrm{Ca}^{2+}\right]_{i}$ rise activates PKC ( $[\mathrm{PKC}]_{\mathrm{A}}$ rise). (c) ATP release after $[\mathrm{PKC}]_{\mathrm{A}}$ accumulate over threshold value. (d) $\left[\mathrm{IP}_{3}\right]$ rise quickly when ATP release from mast cell and act on purinergic receptors of the cell. 
Table I Model parameters and initial resting values.

\begin{tabular}{|c|c|c|}
\hline Parameter & Value & Source \\
\hline$\overline{D_{\mathrm{ATP}}}$ & $3 \times 10^{-10} \mathrm{~m}^{2} \mathrm{~s}^{-1}$ & [31] \\
\hline$V_{\text {ATP }}$ & $0.1 \mathrm{~s}^{-1}$ & evaluated from [31] \\
\hline$\left[\mathrm{PKC}_{A}\right]_{\min }$ & $1.2 \times 10^{-7} \mathrm{M}$ & \\
\hline$k_{\text {loss }}$ & $30 \mathrm{~s}^{-1}$ & {$[31]$} \\
\hline$K_{\text {rel }}$ & $1 \times 10^{-5} \mathrm{M}$ & [31] \\
\hline gATP & $0.15 \mathrm{mS} \mathrm{cm}^{-2}$ & evaluated from [32] \\
\hline$a_{\mathrm{m}}$ & $1000 \mathrm{~s}^{-1}$ & evaluated from [32] \\
\hline$\beta_{\mathrm{m}}$ & $5 s^{-1}$ & {$[32]$} \\
\hline$a_{\mathrm{h}}$ & 0 & [32] \\
\hline$\beta_{\mathrm{h}}$ & $0.01 \mathrm{~s}^{-1}$ & {$[32]$} \\
\hline$[\mathrm{ATP}]_{\mathrm{act} 1 / 2}$ & 20 & \\
\hline$r$ & 0.0244 & {$[37]$} \\
\hline$\lambda$ & 0.08 & [38] \\
\hline$R a$ & $100 \Omega \mathrm{cm}$ & [39] \\
\hline$C_{\mathrm{m}}$ & $0.75 \mu \mathrm{F} \mathrm{cm}^{-2}$ & [39] \\
\hline \multicolumn{3}{|l|}{ initial resting values: } \\
\hline$\left[P K C_{\mathrm{A}}\right]$ & $1 \times 10^{-7} \mathrm{M} \mathrm{s}^{-1}$ & evaluated from [17] \\
\hline$m_{0}$ (initial value of $m$ ) & 0 & \\
\hline$h_{0}($ initial value of $h)$ & 1 & \\
\hline$\left[\mathrm{Ca}^{2+}\right]_{i}$ & $1 \times 10^{-7} \mathrm{M}$ & [31] \\
\hline$\left[\mathrm{Ca}^{2+}\right]_{e}$ & $2 \times 10^{-3} \mathrm{M}$ & [31] \\
\hline$\left[\mathrm{Ca}^{2+}\right]_{E R}$ & $5 \times 10^{-4} \mathrm{M}$ & [37] \\
\hline$E_{\mathrm{m}}$ & $-65 \mathrm{mV}$ & [39] \\
\hline
\end{tabular}

\subsection{Nerve cells responses to ATP stimuli}

Application of ATP to nerve cells activates membrane currents $I_{\mathrm{ATP}}=I_{\mathrm{ATP}, \mathrm{K}}+I_{\mathrm{ATP}, \mathrm{Ca}}+I_{\mathrm{ATP}, \mathrm{Na}}$ and
$\left[\mathrm{Ca}^{2+}\right]_{\mathrm{i}}$ rise. By whole-cell patch-clamp, Tan et al. investigate the relationship of $I-V$ for the VS type of $I_{\text {ATP }}$ (at $10^{-4} \mathrm{M}$ ATP) in rat nodose ganglion (NG) neurons [32]. Fig. 3a showed our simulation results of $I_{\mathrm{ATP}}$ which are in accordance to Tan et al's experiment data. This comparison supports our hypothesis that there were cationic currents activated by ATP stimuli. Nunes et al. observed ATP $\left(2.5-10 \times 10^{-4} \mathrm{M}\right)$ induced three temporal response patterns of $\left[\mathrm{Ca}^{2+}\right]_{\mathrm{i}}$ rise in the petrosal ganglion of rat, and the slow rise and a slow decay type (R2) predominate $\left[\mathrm{Ca}^{2+}\right]_{\mathrm{i}}$ in the younger animals [40]. Fig. $3 \mathrm{~b}$ showed the simulation results of $\left[\mathrm{Ca}^{2+}\right]_{\mathrm{i}}$ in responses to ATP stimuli which are in accordance with the $\mathrm{R} 2$ response of Nunes et al. 's experiment data. $I_{\text {ATP }}$ brings the membrane potential towards the threshold for triggering action potentials, and as the cable theory describing, local membrane potential induce electrical current along the axons and fibers of nerve cells which triggers action potentials propagation. Fig. 4a showed the local action potentials induced by $I_{\mathrm{ATP}}$ when block the cable effect. Fig. $4 \mathrm{~b}$ showed the action potentials propagation along nerve cells induced by the electrical currents from its "upstream" neighbors.

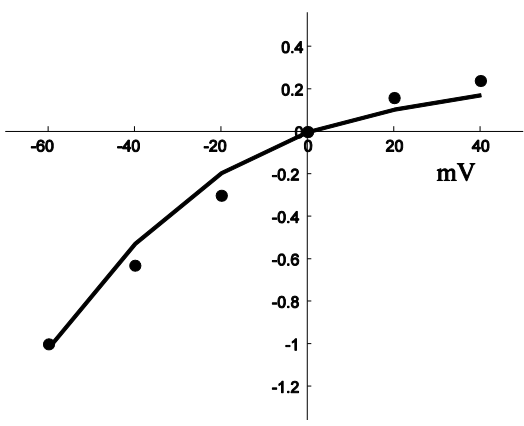

(a)

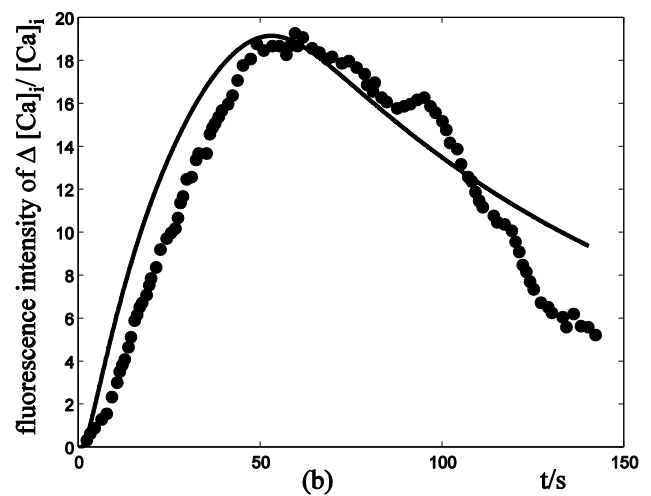

Figure 3 Response of $I_{\text {ATP }}$ and $\left[\mathrm{Ca}^{2+}\right]_{i}$ in a single isolated nerve cell model to ATP stimuli. solid line represents simulation results, filled circles represent the experimental data. (a) sequential current trace of $I_{\text {ATP }}$ with the cell clamped at different holding potentials ranging from -60 to $+40 \mathrm{mV}$. (b) $\left[\mathrm{Ca}^{2+}\right]_{i}$ responses after its exposure to an initiating ATP stimuli during time $\mathrm{t}=0-30 \mathrm{~s}$.
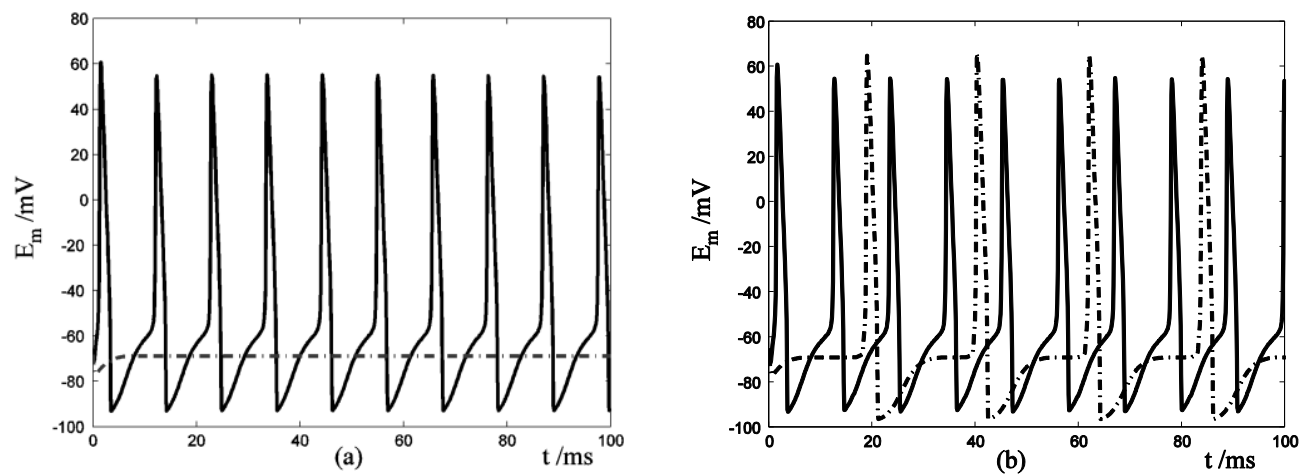

Figure 4 Response of $E_{\mathrm{m}}$ in a single isolated nerve cell model to ATP stimuli. Solid line represents simulation results of the segment exposed to an initiating ATP stimuli, dash line represents simulation results of the segment without ATP stimuli. (a) block the cable current from the activated segment to other segment of the nerve cell. (b) include cable current from the activated segment to other segment of the nerve cell. 


\subsection{Mast cell-nerve cell interaction at acupoint}

Nerve cells share perivascular localization with mast cells and can be activated by ATP release from mast cells. Figs. 5-6 shows the coupled responses of a mast cell (at $r=0$ ) and nerve cells (at $r=D_{\text {ist }} \mathrm{S}$ ) to mechanical stimuli at $r=0$. Fig. 5a shows mechanical stimuli induce ATP release from mast cell, then increase $[\mathrm{ATP}]_{\mathrm{e}}$ (the peak near $\mathrm{t}=16 \mathrm{~s} \& \mathrm{r}=0$ ). ATP diffuses in ECS and activate the nearby nerve cells. Fig. $5 \mathrm{~b}$ shows nerve cells at $D_{\text {ist }}<100 \mu \mathrm{m}$ (bright points present there are triggered action potentials) are activated by ATP released from mast cell, while nerve cells at $D_{\text {ist }}>100 \mu \mathrm{m}$ are not activated because [ATP $]_{\mathrm{e}}$ decreases with $D_{\text {ist }}$ increasing and doesn't reach the threshold for triggering action potentials. Fig. 6 shows $E_{\mathrm{m}}$ and $\left[\mathrm{Ca}^{2+}\right]_{\mathrm{i}}$ responses in nearby nerve cells. Fig. 6a shows action potentials are triggered in nerve cells at $D_{\text {ist }}=20 \sim 80 \mu \mathrm{m}$, we extend simulation time to $80 \mathrm{~s}$ to show there are no action potentials in nerve cells at $D_{\text {ist }}>=100 \mu \mathrm{m}$. Fig. $6 \mathrm{~b}$ shows $\left[\mathrm{Ca}^{2+}\right]_{\mathrm{i}}$ rise is independent of action potential, $\left[\mathrm{Ca}^{2+}\right]_{i}$ peak denpends on $D_{\text {ist }} \mathrm{S}$ which means it depends on $[\mathrm{ATP}]_{\mathrm{e}}$. Table 2 summarized the results.

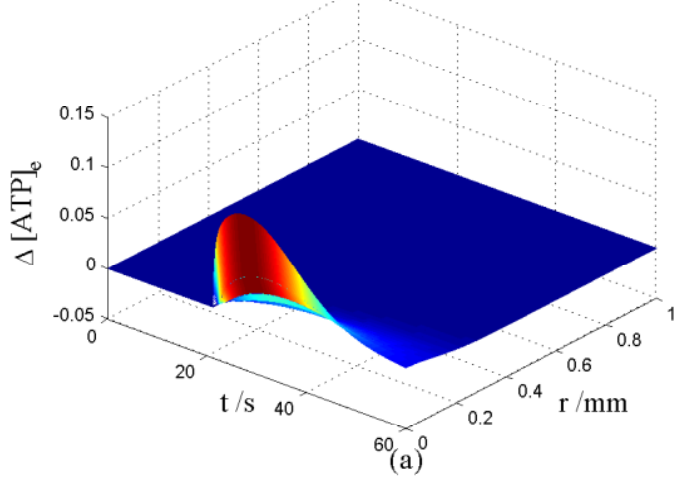

\section{Conclusion and discussion}

\section{I Mechanical stimuli increase $\left[\mathrm{Ca}^{2+}\right]_{i}$ in mast cell and lead to ATP release}

We have shown with our model that mechanical stimuli to a single mast cell leads to both an increase in $\left[\mathrm{Ca}^{2+}\right]_{i}$ as well as the release of ATP, which increases $[\mathrm{ATP}]_{\mathrm{e}}$ and then acts on $\mathrm{P}_{2}$-receptors of the cell in an autocrine manner. Osipchuk reported a wave-like spread of rise in $\left[\mathrm{Ca}^{2+}\right]_{i}$ could be elicited by mechanical perturbation of a single cell in a cluster of cells [41]. Furthermore, both application of either a desensitizing concentration of ATP or $\mathrm{P}_{2}$-receptors antagonist (suramin) inhibited the spread rise initiated by mechanical stimulation of a single cell, suggesting that ATP release from mast cell when stimulated and lead to the spread of $\left[\mathrm{Ca}^{2+}\right]_{i}$ rise by acting on $\mathrm{P}_{2}$-receptors of the nearby cells.

Table 2 Response time of $E_{\mathrm{m}}$ and $\left[\mathrm{Ca}^{2+}\right]_{i}$ peak of different $D_{\text {ist }} \mathrm{S}$

\begin{tabular}{lll}
\hline$D_{\text {ist }}$ & Response time of $E_{\mathrm{m}}$ & {$\left[\mathrm{Ca}^{2+}\right]_{\text {i }}$ peak $(\mu \mathrm{M})$} \\
\hline $2 \times 10^{-5} \mathrm{~m}$ & $22 \mathrm{~s}$ & 0.33 \\
$4 \times 10^{-5} \mathrm{~m}$ & $24 \mathrm{~s}$ & 0.31 \\
$6 \times 10^{-5} \mathrm{~m}$ & $27 \mathrm{~s}$ & 0.29 \\
$8 \times 10^{-5} \mathrm{~m}$ & $33.1 \mathrm{~s}$ & 0.27 \\
$1 \times 10^{-4} \mathrm{~m}$ & No & 0.24 \\
\hline
\end{tabular}

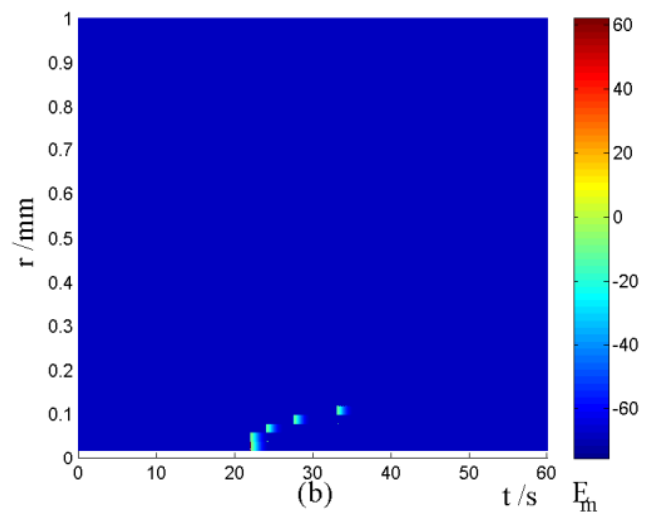

Figure 5 Changes in $[A T P]_{e}$ and $\left[\mathrm{Ca}^{2+}\right]_{i}$ in the coupled mast cell and nerve cell model, as functions of time (t) and radius distance (r), after its exposure to an initiating mechanical stimuli at $r=0$ during time $t=0-60 s$. (a) $[A T P]_{e}$ contour in $E C S$. (b) $E_{m}$ response in nerve cells.
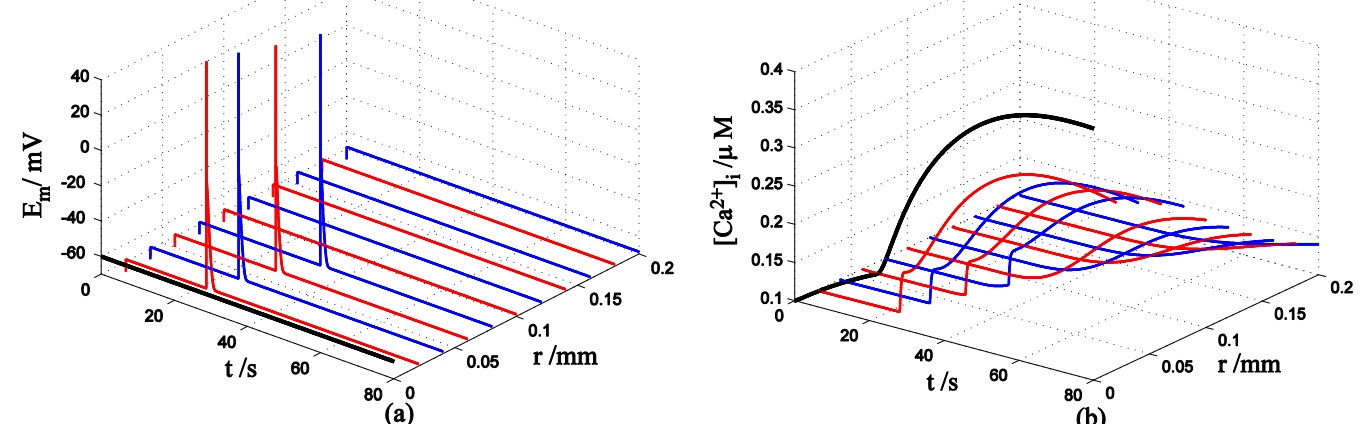

(b)

Figure 6 Responses in $E_{\mathrm{m}}$ and $\left[\mathrm{Ca}^{2+}\right]_{\mathrm{i}}$ in nerve cells at different $D_{\text {ist }}$ in the coupled mast cell and nerve cell model to ATP released from the activated mast cell at $r=0$ by initiating mechanical stimuli during time $t=0-60$ s. (a) $E_{m}$ response. (b) $\left[\mathrm{Ca}^{2+}\right]_{i}$ response. 


\subsection{ATP stimuli activate nerve cells and induce signal transporting in neural network}

We have shown with our model that ATP activates membrane currents $I_{\text {ATP }}$ and triggers action potentials in nerve cells. Because the structure of the neuron (Fig.1), local action potentials will induce electrical current spreading along the fibers or axons of neuron, thus transporting local information to remote regions in neural network. Afferent signal generation occurs at sensory nerve endings, in the mammalian somatosensory system, sensory neurons are responsible for the transduction of peripheral stimuli into action potentials that propagate to the center neural system (CNS) [42], These results can explain the signal spreading in neural system and the results are similar to the action potentials induced by mechanical stimuli in Delmas et al.'s experiment [43].

\subsection{The interaction of mast cell and nerve cell plays a key role in response to mechanical treatment in TCM}

Acupuncture is a method of applying mechanical stimuli into specific parts (acupoints) abundant of mast cells ${ }^{[4]}$. Langevin et al. proposed that the deformation of connective tissue during acupuncture may act as mechanical stimulus on the connective tissue at the cellular level [2-3]. Our experiment showed manual acupuncture stimulation of ST 36 can significantly potentiate the discharge activity of the sciatic nerve and induce degranulation of mast cells at the same time, suggesting an involvement of mast cells in initiating acupuncture signals by peripheral sensory nerve ${ }^{[44]}$, Han CX et al. recorded the specific action potentials on dorsal spinal nerve root when acupuncture is made at Zusanli point with four different acupuncture manipulations [45]. These results are accordance with our model's suggestion. Fig.7 shows the cellular mechanism of mast cell response to acupuncture in TCM. Mechanical stimuli during acupuncture activate mast cells through various receptors which leads to distinct signaling pathways causing the bio-mediators such as ATP release, which has a positive feedback effect to further release. ATP will diffuse in the ECS [46] and activate sensory nerve endings and form electronic signal, electrical current then spreads in neural network and transports local information to neural center. Our experiment indicates mast cells participate in the initiation of manual acupuncture signal in the acupoints ${ }^{[8]}$ and conduct the effective information into centrum by activating the function of nerve cells [47].

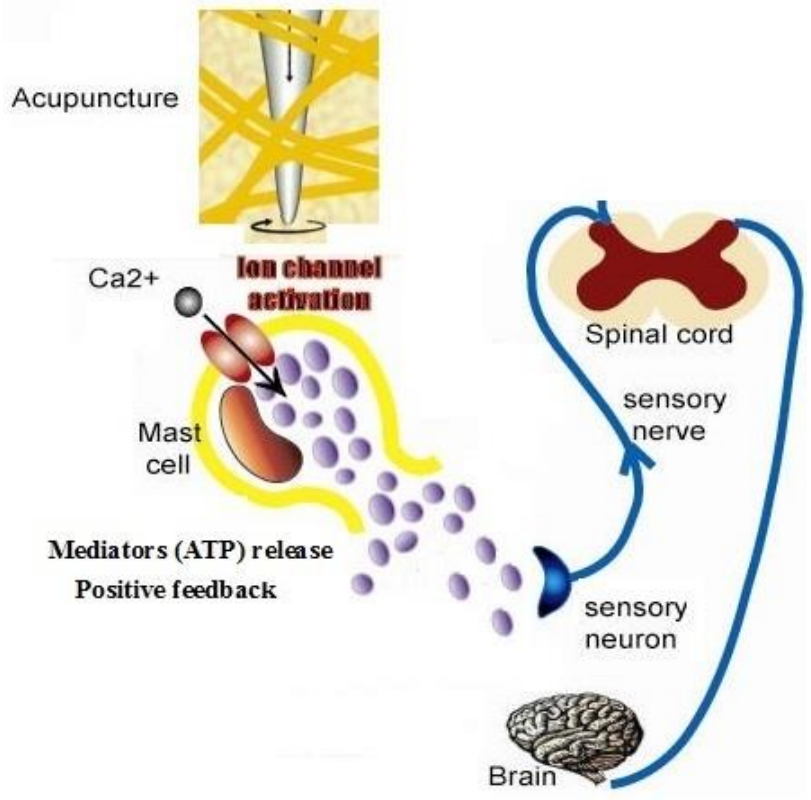

Figure 7 Schematic diagram of cellular mechanism of acupuncture effect.

In this paper, we developed a mathematical model to study $\mathrm{Ca}^{2+}$ signaling and ATP release in mast cell and nerve cell, and applied it to investigate the coupled response of mast cell and nerve cell system to mechanical stimuli. This study facilitates our understanding of the mechanotransduction process in acupoint region (abundant of mast cells and nerve cells) induced by mechanical stimuli, provides a methodology for quantitative analyze acupuncture treatment.

\section{Acknowledgement}

This work was supported by National natural science foundation of China (11202053), Shanghai Science Foundation (12ZR1401100) and 973 project (2012CB518502)

\section{Competing Interests}

The authors have declared that no competing interest exists.

\section{References}

1 Schwarz W, Gu QB. Cellular Mechanisms in Acupuncture Points and Affected Sites. In: Xia Y, Ding DH, Schwarz W, editors. Current research in acupuncture, 1st ed. New York: Springer; 2013: 37-51.

2 Langevin HM, Yandow JA. Relationship of acupuncture points and meridians to connective tissue planes. Anat Rec. 2002; 269: 257-265.

3 Yu XJ, Ding GH, Huang H, et al. Role of collagen fibers in acupuncture analgesia therapy on rats. Connect Tissue Res. 2009; 50: 110-120.

4 Culliton BJ. Acupuncture: fertile ground for faddists and serious NIH research. Science. 1972; 177: 592-594.

5 Bonafede M, Dick A, Noyes K, et al. The effect of acupuncture utilization on healthcare utilization. Med Care. 2008; 46: 41-48.

6 Skaper SD, Facci L. Mast cell-glia axis in neuroinflammation and therapeutic potential of the anandamide congener palmitoylethanolamide. Philos T R Soc B. 2012; 367: 3312-3325

7 Gilfillan AM, Austin SJ, Metcalfe DD. Mast cell biology: introduction and overview. Adv Exp Med Biol. 2011; 716: 2-12. 
8 Ding GH, Zhang D, Huang M, Wang LN, Yao W. Function of Collagen and Mast Cells in Acupuncture Points. In: Xia Y, Ding GH, Schwarz W. Current research in acupuncture, 1st ed. New York: Springer; 2013.

9 Zhang D, Ding GH, Shen XY, et al. Role of mast cells in acupuncture effect: a pilot study. Explore-NY. 2008; 4: 170-177.

10 Wang LN, Ding GH,Gu QB, et al. Single-channel properties of a stretch-sensitive chloride channel in the human mast cell line HMC-1. Eur Biophys J Biophy. 2010; 39: 757-767.

11 Zhang D, Spielmann A, Ding GH, et al. Activation of mast-cell degranulation by different physical stimuli involves activation of the transient-receptor-potential channel TRPV2. Physiol Res. 2012; 61: 113-124.

12 Burger MM, Sordat B, Zinkernagel RM. Cell to cell interaction. Basel: Karger; 1990.

13 Blennerhassett MG,Tomioka M, Bienenstock J. Formation of contacts between mast cells and sympathetic neurons in vitro. Cell Tissue Res. 1991; 265: 121.

14 Arizono N, Matsuda S, Hattori T, et al. Anatomical variation in mast cell nerve associations in the rat small intestine, heart, lung, and skin. Similarities of distances between neural processes and mast cells, eosinophils, or plasma cells in the jejunal lamina propria. Lab Invest. 1990; 62: 626.

15 Göthert M, Garbarg M, Hey JA, et al. New aspects of the role of histamine in cardiovascular function: identification, characterization, and potential pathophysiological importance of H3 receptors. Can J Physiol Pharmacol. 1995; 73: 558-564.

16 Artico M, Iannetti G, Tranquilli Leali FM, et al. Nerve fibers-mast cells correlation in the rat parietal pleura. Resp Physiol. 1998; 113: 181-188.

17 Theoharides TC. The mast cell: a neuroimmunoendocrine master player. Int J Tissue React. 1996; 18: 1-21.

18 Bauer O, Razin E. Mast cell-nerve interactions. News Physiol Sci. 2000; 15: 213-218.

19 Suzuki R, Furuno T, Okamoto K, et al. ATP plays a role in neurite stimulation with activated mast cells. J Neuroimmunol. 2007; 192: 49-56.

20 Bulanova E, Bulfone-Paus S. P2 receptor-mediated signaling in mast cell biology. Purinergic Signal. 2010; 6: 3-17.

$21 \mathrm{Xu} \mathrm{F}$, Lu TJ, Seffen KA. Skin thermal pain modeling-A holistic method. J Therm Bio. 2008; 33: 223-237.

22 Xu F, Wen T, Seffen KA. Modeling of skin thermal pain: A preliminary study. Appl Math Comput. 2008; 205: 37-46.

$23 \mathrm{Xu} \mathrm{F}$, Lu TJ. Skin biothermomechanics: modeling and experimental characterization. Adv Appl Mech. 2009;43: 147-248.

24 Bennett MR, Farnell L, Gibson WG. A quantitative model of cortical spreading depression due to purinergic and gap-junction transmission in astrocyte networks. Biophy J. 2008; 95: 5648-5660.

25 Zhou L, Chui SY. Computer model for action potential propagation through branch point in myelinated nerves. J Neurophysiol. 2001; 85: 197-210.

26 Shi XM, Zheng YF, Liu ZR. A model of calcium signaling and degranulation dynamics induced by laser irradiation in mast cells. Chin Sci Bull. 2008; 53: 2315-2325.

27 Yao W, Huang HX, Ding GH. A dynamic model of calcium signaling in mast cells and LTC4 release induced by mechanical stimuli. Chin Sci Bull. 2013; 59: 956-963

28 Zylka MJ. Needling adenosine receptors for pain relief. Nat Neurosci. 2010; 13: 783-784

29 Goldman N, Chen M, Fujita T, et al. Adenosine A1 receptors mediate local anti-nociceptive effects of acupuncture. Nat Neurosci. 2010; 13: 883-888.

30 Bennett MR, Farnell L, Gibson WG. A quantitative model of purinergic junctional transmission of calcium waves in astrocyte networks. Biophys J. 2005; 89: $2235-2250$

31 Lemon G, Gibson WG, Bennett MR. Metabotropic receptor activation, desensitization and sequestration-I: modelling calcium and inositol 1,4,5 -trisphosphate dynamics following receptor activation. J Theor Biol. 2003; 223: 93-111.

32 Tan Y, Zhao B, Zeng QC, et al. Characteristics of ATP-activated current in nodose ganglion neurons of rats. Neurosci Lett. 2009; 459: 25-29.

33 Koch C, Segev I,et al. Methods in neuronal modeling: from ions to networks, 2nd ed. Cambridge: MIT Press; 1998.

34 Friel DD. [Ca2+]i oscillations in sympathetic neurons: an experimental test of a theoretical model. Biophys J. 1995; 68: 1752-1766.

35 Hines ML, Carnevale NT. The neuron simulation environment. Neural Comput. 1997; 9: 1179-1209.

36 Rinzel J. Electrical excitability of cells, theory and experiment: Review of the Hodgkin-Huxley foundation and an update. B Math Bio. 1990; 52: 3-23.

37 Fink CC, Slepchenko B, Loew LM. Determination of time-dependent inositol-1,4,5-trisphosphate concentrations during calcium release in a smooth muscle cell. Biophys J. 1999; 77: 617-628.

38 Mazel T, Raymond R, Raymond-Stintz M, et al. Stochastic modeling of calcium in 3D geometry. Biophys J. 2009; 96: 1691-1706.

39 Kager H, Wadman WJ, Somjen GG. Simulated seizures and spreading depression in a neuron model incorporating interstitial space and ion concentrations. J Neurophysiol. 2000; 84: 495-512.

40 Nunes AR, Chavez-Valdez R, Ezell T, et al. Effect of development on [Ca2+]i transients to ATP in petrosal ganglion neurons: a pharmacological approach using optical recording. J Appl Physiol. 2012; 112: 1393-1402.
41 Osipchuk Y, Cahalan M. Cell-to-cell spread of calcium signals mediated by ATP receptors in mast cells. Nature.1992; 359: 241-244.

42 Delmas P, Hao JZ, Rodat-Despoix L. Molecular mechanisms of mechanotransduction in mammalian sensory neurons. Nat Rev Neurosci. 2011; 12: 139-153.

43 Hao JZ, Delmas P. Multiple desensitization mechanisms of mechanotransducer channels shape firing of mechanosensory neurons. J Neurosci. 2010; 30: 13384-13395.

44 SA ZY, Huang M, Zhang D, et al. Relationship between Regional Mast Cell Activity and Peripheral Nerve Discharges during Manual Acupuncture Stimulation of "Zusanli"(ST36). Acupuncture Research. 2013; 38:118-122.

45 Han CX, Wang J, Che YQ, et al. Nonlinear characteristics extraction from electrical signals of dorsal spinal nerve root evoked by acupuncture at Zusanli point. Acta physica sinica. 2010; 59: 5881-5888.

46 Yao W, Li YB, Ding GH. Interstitial fluid flow: the mechanical environment of cells and foundation of meridians. Evid-Based Compl Alt, 2012; ArticleID853516. doi:10.1155/2012/853516.

47 Huang M, Zhang D, Sa ZY, et al. In adjuvatn-induced arthritic rats, acupuncture analgesic effects are histamine dependent: potential reasons for acupoint preference in clinical practice. Evid-Based Compl Alt. 2012, Article ID 810512, doi:10.1155/2012/810512. 